\title{
New Insights into Nanoindentation-Based Adhesion Testing
}

\author{
A. KLEINBICHLER, ${ }^{1,2}$ M.J. PFEIFENBERGER, ${ }^{2}$ J. ZECHNER, ${ }^{1}$ \\ N.R. MOODY, ${ }^{3}$ D.F. BAHR, ${ }^{4}$ and M.J. CORDILL ${ }^{2,5}$ \\ 1.-KAI-Kompetenzzentrum Automobil und Industrieelektronik GmbH, Technologiepark \\ Villach, 9524 Villach, Austria. 2.-Erich Schmid Institute for Material Science, Austrian Academy \\ of Sciences and Department of Material Physics, Montanuniversität Leoben, 8700 Leoben, \\ Austria. 3.-Sandia National Laboratories (Retired), Livermore, CA 94550, USA. 4.-School of \\ Materials Engineering, Purdue University, West Lafayette, IN 47907, USA. 5.-e-mail: \\ megan.cordill@oeaw.ac.at
}

\begin{abstract}
Nanoindentation, or instrumented indentation, is a versatile technique that is most often used to measure the elastic modulus and hardness of thin film systems. It can also be employed to measure thin film adhesion energies by producing well-defined areas of delamination. When combined with the proper mechanics-based model and characterization of the failing interfaces, nanoindentation-induced delamination is a powerful tool to quantify interfacial fracture. This article highlights new improvements to the technique that build off the work of Marshall and Evans in the 1980s. Indentation-induced delamination in systems with brittle films or substrates can be a balance between causing delamination and causing through-thickness or bulk fracture. Focused ion beam cross-sectioning and confocal laser scanning microscopy were used to characterize failing interfaces, additional fracture events were observed in the load-displacement curves, and the adhesion energy was determined using not only symmetric, ideally shaped buckles, but also irregular-shaped and half-delaminated buckles.
\end{abstract}

\section{INTRODUCTION}

Thin film adhesion has been investigated since the early days of fabrication in the fields of microelectronics and protective coatings. Early pioneers such as Mittal, Weaver, and Chapman ${ }^{1-3}$ helped define the field of thin film adhesion and brought testing methods to the forefront during the late 1970s and 1980s. These early adhesion tests were mostly qualitative or semiquantitative measurements and included peel tests, tape tests, scratch and lap shear tests. In the late 1980s and 1990s, a new generation of materials scientists and mechanics researchers introduced indentation-based techniques, stressed overlayers, four point bending, and bulge testing with their appropriate models to quantify the adhesion energy of an interface. ${ }^{4-11}$ These methods and combinations of methods have now become commonplace for those researchers working in the thin film adhesion area. ${ }^{12-16}$

Having well-adhering films for micro and nanoelectronics, hard coatings, and flexible electronics is still a challenge as well as a fruitful area of research and development. Films are becoming both thinner and thicker, more chemically complex, and substrates are becoming more diverse (metals, ceramics, polymers, etc.). There is continued growth in technique development to quantify interface adhesion and to tackle the new interfaces and film systems. Some use indentation, ${ }^{17,18}$ whereas others use complex micro-mechanical bending geometries and perform the experiments in situ with picoindenters in the scanning electron microscope (SEM) or transmission electron microscope (TEM) ${ }^{19,20}$ In the flexible electronics area (films on compliant polymer substrates), tensile-induced delamination is prominent. ${ }^{21,22}$ Nanoindentation, focused ion beam (FIB) milling, and confocal laser scanning microscopy (CLSM) are bringing more insight to adhesion testing as well as increasing the imaging areas compared with other available methods (atomic force microscopy (AFM) or profilometry). Nanoindenters are now a basic measurement tool at most research institutes, and their practicality for these tests increases when scratching and imaging are used in conjunction with the more 
common indenting procedures. FIB allows for sitespecific cross-sectioning at the microscale to quickly identify a failing interface and additional fracture events that may have occurred with an indent or a scratch. FIB is also useful to create transmission electron microscopy samples using the lift-out method for the examination of a film microstructure and interface structure. CLSM is a 3D surface imaging technique that is ten times faster than AFM and has a higher resolution compared with a profilometer. With this technique, larger delaminations, both in height and width, can be analyzed and used to measure adhesion. ${ }^{23}$

An early indentation-induced interfacial fracture test was developed by Marshall and Evans., Improvements and updates to the original models of Marshall and Evans ${ }^{5}$ and Hutchinson and Suo ${ }^{10}$ were added by Kriese et al. ${ }^{9}$ and Cordill et al. ${ }^{12}$ Briefly, the Marshall and Evans model required that the indent volume remains within the film (Fig. 1a). This implies that the substrate does not deform under the indent, nor does the formation of pile-ups around the indent occur. It is important that the volume of the indent remains within the film thickness because the stress induced by the indent is used in the model and works well for thick films on hard and stiff substrates. When the film thickness is reduced, causing a delamination where the indent remains in the film is difficult. By adding a stressed overlayer, as performed by Kriese et al. ${ }^{9}$ (Fig. 1b), the depth of the indent could be increased and the possibility of blister formation could be increased as a result of a compressive stress in the overlayer. Kriese et al. also introduced an extended model for the buckling of a bilayer system. Additional advancements ${ }^{12}$ helped determine when an indentation delamination was a pinned or unpinned circular blister (Fig. 1c and d) and when the indent volume can be ignored as a result of substrate deformation. More work is still being performed on how the load-displacement curves can be better used to determine delamination and buckle formation, for example, with acoustic emission analysis. ${ }^{24}$ Nevertheless, cross-sectioning with the FIB is an efficient method to use for the interpretation of the load-displacement curve, and it allows for the observation of the failing interface as well as of any interface or substrate fracture events that can result in pop-ins in the load-displacement curves. Film and substrate deformation of the indent as well as the pinned/unpinned buckle geometry can also be assessed better with FIB cross-sectioning. Most of these fracture events cannot be observed using in-situ indentation in the SEM because they occur under the indent. Evaluation of adhesion energies is enhanced with knowledge of how the film and substrate are deforming or fracturing.

This study will demonstrate the use of nanoindentation-based techniques to measure the adhesion of barrier layers. Barrier layers provide chemical stability to conductive metallizations for
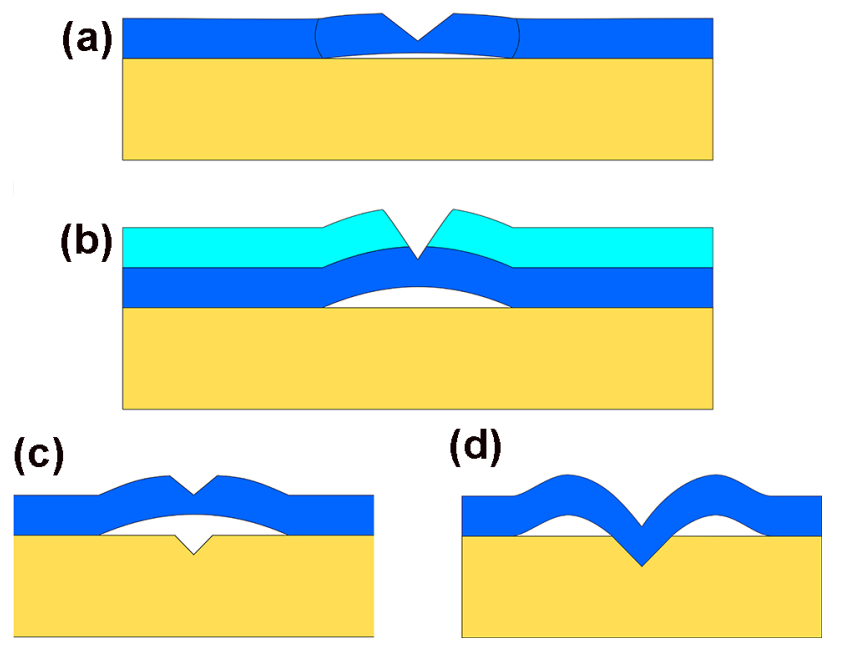

Fig. 1. Nanoindentation-induced delamination models by (a) Marshall and Evans, (b) Kriese et al. with a stressed overlayer, and Cordill et al. with (c) unpinned and (d) pinned buckle geometries.

microelectronic devices. A prime example is silicon nitride, $\mathrm{Si}_{3} \mathrm{~N}_{4}$, which is used as an ion-barrier material, oxidation barrier, insulator, or etch mask. By using a Tungsten-Titanium (WTi) stressed overlayer combined with nanoindentation, well-defined areas of delamination can be produced. The produced delaminations were measured with AFM and CLSM, whereas FIB cross-sectioning was used to identify the failing interface and additional fracture and deformation events present in the load-displacement curves. The combination of the two characterization techniques will be shown to improve the understanding of the evolution of the buckles under indentation loading.

\section{MATERIALS AND EXPERIMENT}

The samples investigated consisted of silicon wafers (725 $\mu \mathrm{m}$ thick) with $800 \mathrm{~nm}$ of borophosphosilicate glass (BPSG) deposited using plasma-enhanced chemical vapor deposition (PECVD), followed by $400 \mathrm{~nm}$ of PECVD silicon nitride $\left(\mathrm{Si}_{3} \mathrm{~N}_{4}\right)$. To act as an adhesion and diffusion barrier layer, a $300 \mathrm{~nm}$ thick Tungsten-Titanium (WTi) film was sputter deposited on the $\mathrm{Si}_{3} \mathrm{~N}_{4}$ where the tungsten film contained 20 at.\% of Ti. The WTi film was deposited under conditions that induced a compressive residual stress of about $1.5 \mathrm{GPa}$ (measured with x-ray diffraction).

Nanoindentation was conducted with a Keysight G200 nanoindenter. A $90^{\circ}$ conical diamond tip with a $1-\mu \mathrm{m}$ tip-diameter and a load range between $100 \mathrm{mN}$ and $500 \mathrm{mN}$ was used to generate indentation-induced delamination. Fifteen indents were made per maximum load in this range, which was increased in intervals of $50 \mathrm{mN}$. The indents were set in a grid being $250 \mu \mathrm{m}$ apart from each other to avoid any interaction of the formed blisters, indent plastic zones, or fracture events. After indentation, 
all resulting delaminations were imaged with an AFM (Veeco Dimension DI3000) or CLSM (Olympus LEXT OLS 4100). The buckle measurements were made from the AFM and CLSM images using Gwyddion, ${ }^{25}$ and the model of Hutchinson and Suo ${ }^{10}$ was modified for a bi-layer film using the theory of Kriese et al. ${ }^{9}$ to calculate film stresses and adhesion energies. The elastic modulus of WTi was determined from nanoindentation experiments using the continuous stiffness method and a wellcalibrated Berkovich tip at $E=171.8 \mathrm{GPa}$. The Poisson's ratio of WTi was estimated using a simple rule of mixture with $v=0.288$. The modulus and Poisson's ratio of $\mathrm{Si}_{3} \mathrm{~N}_{4}$ were taken from Vlassak et al. ${ }^{26}$ where these properties $E=222 \mathrm{GPa}$ and $v=0.27$ were measured by bulge testing.

Cross sections were made using a femtosecond laser and FIB. A femtosecond pulsed laser, which provides an ablation rate four to six orders of magnitude higher than a $\mathrm{Ga}^{+}$ion beam, ${ }^{27}$ was used to reduce the time needed for the rough cut of the buckle cross section. The use of a femtosecond pulsed laser allows structuring of materials with ideally no heat affected zone as a result of the ultrashort pulse duration, but the shock wave of the ablation process can lead to the injection of dislocations. The amorphization of $\mathrm{Si}$, or periodic surface structures in the range of a few hundred nanometers in depth, are generated when using a laser in the ultrashort pulse regime. ${ }^{28}$ For the investigation of the failing interfaces, these modifications needed to be removed, thus, requiring a polishing step with the FIB. In this study, a recently developed prototype, which combines the high material removal rate of a femtosecond pulsed laser with the high precision of a FIB, was used. ${ }^{29}$

The cross section processing route employing the femtosecond laser is sketched in Fig. 2. For each cross section, a line first cut with the femtosecond laser serves as a pre-preparation step (indicated as green dashed lines in Fig. 2). Afterward the final cross section is polished via FIB milling (indicated as orange rectangles in Fig. 2). The laser prepreparation step used a laser wavelength of $515 \mathrm{~nm}$, a laser pulse repetition rate of $1 \mathrm{kHz}$, a pulse duration of $318 \mathrm{fs}$, and a fluence of $0.52 \mathrm{~J} / \mathrm{cm}^{2}$. For this step, a $150-\mu \mathrm{m}$-long line was scanned with $1 \mathrm{~mm} / \mathrm{s}$ in 60 passes and took only about $10 \mathrm{~s}$. The focal spot diameter of approximately $25 \mu \mathrm{m}$ accounts for the width of the laser cut as can be seen in the top view in Fig. $2 \mathrm{a}$ and c. For the subsequent FIB milling, a current of $2 \mathrm{nA}$ and an accelerating voltage of $30 \mathrm{kV}$ were used. Exemplary for an $8 \times 80 \mu \mathrm{m}^{2}$ large rectangle milled in 1 pass, the processing time was $1,000 \mathrm{~s}$. Figure $2 \mathrm{~b}$ and $\mathrm{d}$ show the FIB polished cross sections in a tilted view.

\section{Indentation-Induced Delaminations}

Indentations with loads between $300 \mathrm{mN}$ and $500 \mathrm{mN}$ in the WTi-Si $\mathrm{N}_{3}$ film system produced delaminations. At higher loads $(400-500 \mathrm{mN})$, the buckles partially or completely spalled from the substrate. Buckles usable for adhesion measurements were produced in the load range of 300-350 $\mathrm{mN}$ (Fig. 3). For this study, 13 buckles without spallation having a symmetric circular shape were analyzed. The buckles often exhibited significant radial cracking at loads higher than $300 \mathrm{mN}$, and indents made with lower loads showed almost no radial cracking. Indents with loads lower than $250 \mathrm{mN}$ did not produce buckles. By investigating the spallation areas of the indents in the CLSM images it can be determined that the failing interface is the $\mathrm{Si}_{3} \mathrm{~N}_{4}$-BPSG. Nevertheless, information about any substrate fracture events observed in the load-displacement curves (Fig. 4) cannot be investigated.

The FIB cross sections revealed that during indenting, multiple forms of cracking occurred in the film stack. For the indents at the $250 \mathrm{mN}$ interface, delamination was not produced and the cross section shows no observable interface fracture (Fig. 4a). Nevertheless, cracks in the $\mathrm{Si}_{3} \mathrm{~N}_{4}$ film can be observed directly under the indent, which can be linked to the pop-in event in the load-displacement curve. Of interest is that the indent deforms the lower BPSG layer and the WTi and $\mathrm{Si}_{3} \mathrm{~N}_{4}$ thicknesses remain constant under the indent. At $300 \mathrm{mN}$, multiple interfaces have separated as shown in Fig. 4b and c. Interface cracks develop between the $\mathrm{Si}_{3} \mathrm{~N}_{4}$ and the BPSG as well as between the BPSG and the Si. The interface crack between BPSG and Si originates directly under the indenter tip, extends for a few micrometers, and eventually kinks up to the $\mathrm{Si}_{3} \mathrm{~N}_{4}$ interface (Fig. 4b). This type of fracture under the indenter has been observed in other film systems. ${ }^{30}$ Once the interface crack has kinked, it propagates along the $\mathrm{Si}_{3} \mathrm{~N}_{4}$-BPSG interface until it either extends for another $30 \mu \mathrm{m}$ to become a small buckle (Fig. 4b) or it grows a further $70 \mu \mathrm{m}$ into a large buckle (Fig. 4c). It can be seen from the cross section in Fig. $4 \mathrm{~b}$ that the small buckle is a result of two interfaces separating $\left(\mathrm{Si}_{3} \mathrm{~N}_{4}\right.$-BPSG and BPSG-Si) and the kinking of the crack rather than a single interface separation. This tortuous crack path influences the calculation of the adhesion energy using the buckle in Fig. 4b.

Figure $4 \mathrm{c}$ shows that the interface crack between the $\mathrm{Si}_{3} \mathrm{~N}_{4}$ and the BPSG extends much farther (70 $\mu \mathrm{m}$ in width) and that the buckle height is increased $(2-3 \mu \mathrm{m})$; the interface crack then propagates until it kinks through the $\mathrm{Si}_{3} \mathrm{~N}_{4}$ film as shown in the inset of Fig. 4c. Hence, the whole buckle is the result of this interface separation and is indicated in the load-displacement curve in Fig. 4c, where a large pop-in occurred during the hold time at a load of $300 \mathrm{mN}$. The cross section also shows the fracture under the indenter tip extended through the BPSG and into the Si substrate as a single vertical crack. When the load was increased to $350 \mathrm{mN}$ film, failure occurred in two ways. The interface crack propagates similar to the case of a 

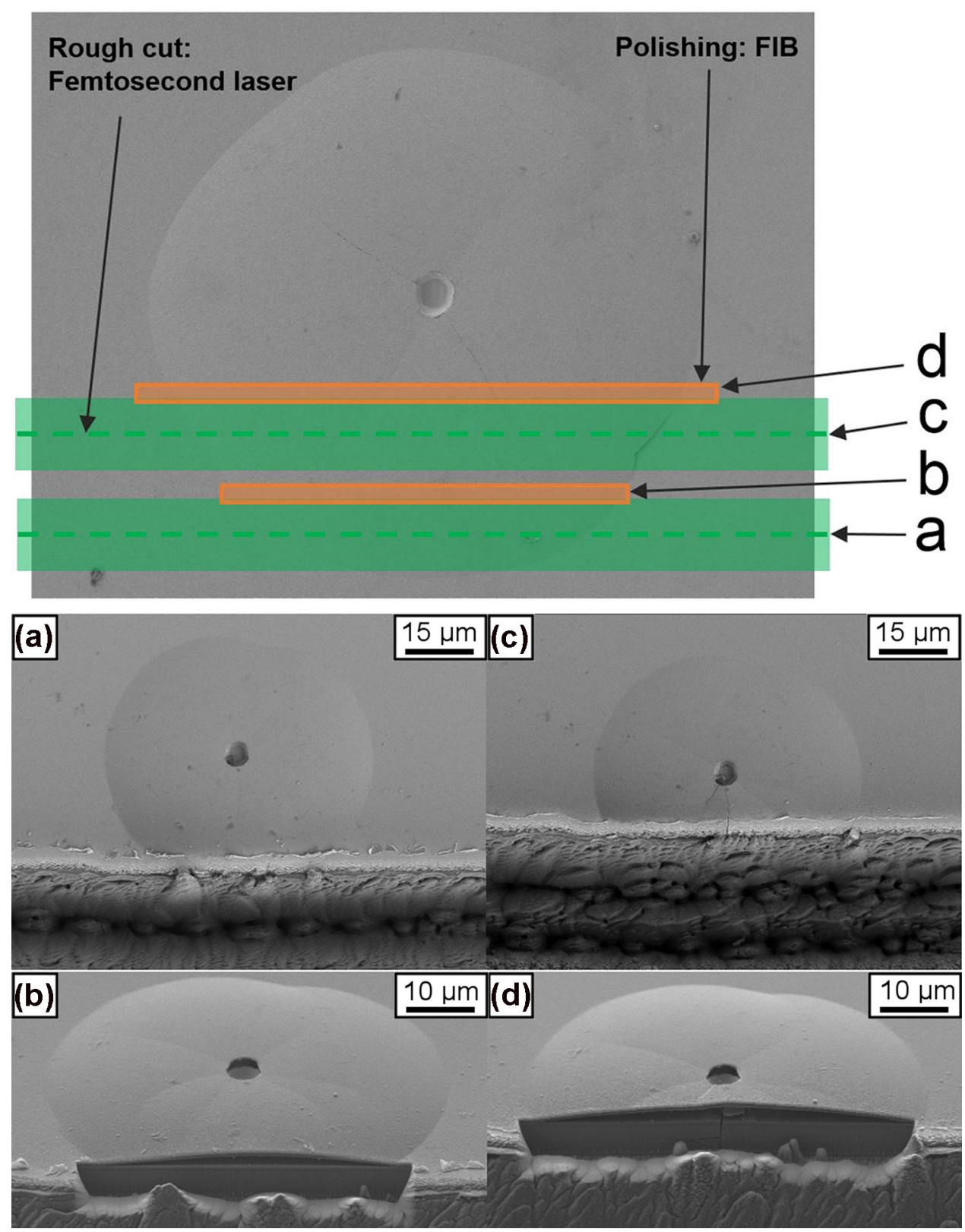

Fig. 2. Route for the processing of large buckle cross sections using a femtosecond laser and a FIB. (a) and (c) show the sample after the femtosecond laser rough cuts. (b) and (d) display the FIB polished cross sections in a tilted view (Color figure online).

$300 \mathrm{mN}$ load, forming a large buckle with a diameter of about $70 \mu \mathrm{m}$, or the interface crack kinks toward the surface during interface crack propagation and spallation occurs, as shown in Fig. 4d. Both of these events are indicated in the load-displacement curve by a large pop-in event between $300 \mathrm{mN}$ and $350 \mathrm{mN}$, as shown in Fig. $4 \mathrm{~d}$ for a spalled buckle. From the pop-in events alone, it is not possible to differ between buckle formation and spallation (compare load-displacement curves of Fig. 4c and d). Some buckles produced were irregularly shaped and with localized spallation and chipping which created half-buckles (box in Fig. 3).
Additionally, although the small buckles show no sign of radial cracking around the indent, the large buckles do and the extent increases with increasing load (Fig. 4c), which aids the spallation of the buckle (Fig. 4d). In this particular system, the WTi film acts as a stressed overlayer with its large residual compressive stress, helping to control the delamination of the $\mathrm{Si}_{3} \mathrm{~N}_{4}$ barrier layer as well as supporting this brittle film to prevent it from spalling from the BPSG. As seen in Fig. 4d, the $\mathrm{Si}_{3} \mathrm{~N}_{4}$ film cracks at the base of the buckles causing spallation before adhesion could be measured. The FIB cross sections also confirm that the indentation 


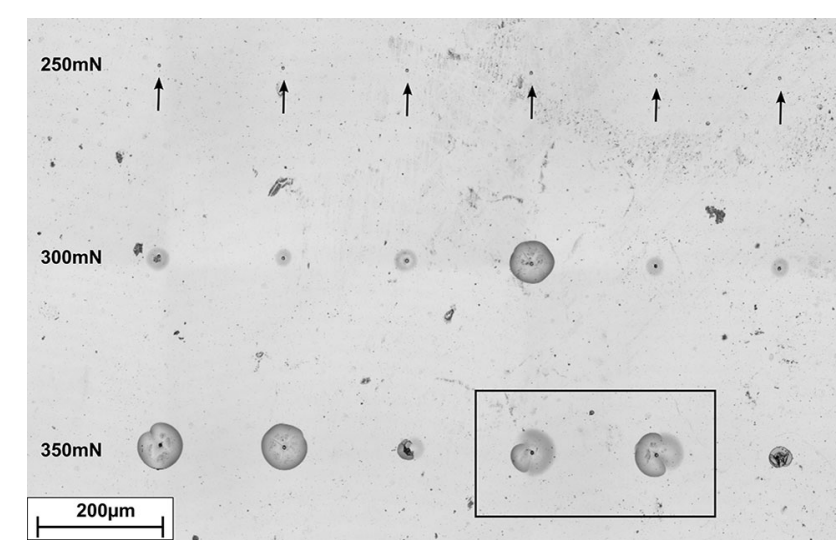

Fig. 3. Indentation buckle overview in a load range of $250-350 \mathrm{mN}$. Indents made with $250 \mathrm{mN}$ did not produce buckles (indicated by arrows). At $300 \mathrm{mN}$, two sizes of buckles were produced, small (about $30 \mu \mathrm{m}$ width) and large (about $60 \mu \mathrm{m}$ width). Loads of $350 \mathrm{mN}$ resulted in two types of delamination, either large circular buckles or film spallation. The box indicates the half-buckles that are discussed in Table I.

buckles have an unpinned geometry because the indents were not connected to the substrate at the center of the indent.

A range of loads and number of indents is necessary to understand how delamination and fracture events transpire. As demonstrated in Fig. 4, pop-ins do not always indicate interface fracture and can relate to fracture events of the underlying films or substrate. The FIB cross sections also identified that the WTi, $\mathrm{Si}_{3} \mathrm{~N}_{4}$, and BPSG films co-deformed, most likely as a result of the low modulus of the BPSG $(E=70 \mathrm{GPa})$. With this hardon-soft system, Marshall and Evans should not be applied as the volume of the indent would be challenging to determine. Large pop-ins correlated to the interface fracture and occurred at approximately the same load in this system (around $300 \mathrm{mN}$ ). Yet not all film-substrate systems will behave in such a repeatable manner and should be carefully characterized.

\section{Quantifying the Adhesion Energy}

A large and a small buckle, similar to those in Fig. $4 \mathrm{~b}$ and c, used for adhesion calculation are shown in Fig. 5. The model is only valid for buckles with a symmetric circular shape. The small buckles were imaged by AFM (Fig. 5a and b), the large buckles were imaged with CLSM (Fig. $5 \mathrm{c}$ and d ${ }^{31}$ because the buckle dimensions were too large for AFM. Buckle heights and widths from each buckle were used to calculate the adhesion energy from the profiles indicated in Fig. 5.

The profiles of the AFM and CLSM images and FIB cross-sectioning suggest that the indentation buckles can be modeled as unpinned circular buckles according to Hutchinson and Suo. ${ }^{10}$ Marshall and Evans is not used in this case because the indent does not remain within the film thickness and deforms the substrate. Only buckles that are much larger than the indentation imprint with a continuous circular base and very little radial cracking should be used for adhesion calculation. ${ }^{12}$ The adhesion of the $\mathrm{Si}_{3} \mathrm{~N}_{4}$-BPSG interface has been calculated using the Hutchinson and Suo model ${ }^{10}$ where the stresses and the interfacial fracture energies can be calculated using the geometry of the produced buckles. The necessary measurements are the buckle height, $\delta$; buckle width, $2 b$; as well as the thicknesses of the buckling films, $h_{i}$, where the index $i=1,2$ denoting the sequence of the films starting from the surface, as well as the elastic moduli, $E_{i}$, and the Poisson's ratios, $v_{i}$, of the contributing films. In the case of a multilayered film, the model of Kriese et al. was used, where a combined second moment of inertia, $I_{\mathrm{T}}$, is calculated for the buckling WTi- $\mathrm{Si}_{3} \mathrm{~N}_{4}$ film system, ${ }^{9}$ using:

$$
I_{\mathrm{T}}=\sum_{i=1}^{2} \frac{1}{12} n_{i} k h_{i}^{3}+n_{i} k h_{i}\left(\bar{Y}-y_{i}\right)^{2}
$$

For definitions of all variables, the reader is referred to the supplemental material. This moment of inertia is then used to calculate the critical buckling stress, $\sigma_{\mathrm{b}}$ :

$$
\sigma_{\mathrm{b}}=\frac{\mu^{2}}{k h b^{2}}\left[\frac{E_{1}}{1-v_{1}^{2}}\right]\left(I_{\mathrm{T}}\right)
$$

with $\mu^{2}=14.68$ for an unpinned buckle, ${ }^{10,12} h$ is the total thickness of the buckling films, and $E_{1}$ and $v_{1}$ are the elastic modulus and Poisson's ratio of the WTi top layer, respectively. The driving (or residual) stress, $\sigma_{\mathrm{d}}$, can be calculated by: ${ }^{10}$

$$
\sigma_{\mathrm{d}}=\sigma_{\mathrm{b}}\left[c_{1}(\delta / h)^{2}+1\right]
$$

with $c_{1}=0.2473(1+v)+0.2231\left(1-v^{2}\right)$ for circular indentation buckles. Using the stresses calculated with Eqs. 2 and 3, the mixed-mode adhesion energy for the indentation buckles is:

$$
\Gamma(\Psi)=c_{2}\left[1-\left(\sigma_{\mathrm{b}} / \sigma_{\mathrm{d}}\right)^{2}\right] \frac{\left(1-v_{\mathrm{w}}\right) h \sigma_{\mathrm{d}}^{2}}{E_{\mathrm{w}}}
$$

with $c_{2}=\left[1+0.9021\left(1-v_{\mathrm{w}}\right)\right]^{-1}$, and $E_{\mathrm{w}}$ and $v_{\mathrm{w}}$ are the elastic modulus and Poisson's ratio of the whole buckling system, respectively. ${ }^{9}$ The mixed-mode adhesion energy calculated from Eq. 4 is a measure for the practical work of adhesion because it depends on the phase angle of loading, $\Psi$, which gives the relation between normal and shear forces present at the interface. A more detailed discussion on mode mixity can be found in the supplemental material.

The mixed-mode adhesion energies calculated from the different indentation buckles produced are summarized in Table I to demonstrate how the buckle shape, size, and fracture behavior influences the calculation of the adhesion energies and the associated buckling stresses. When comparing the 

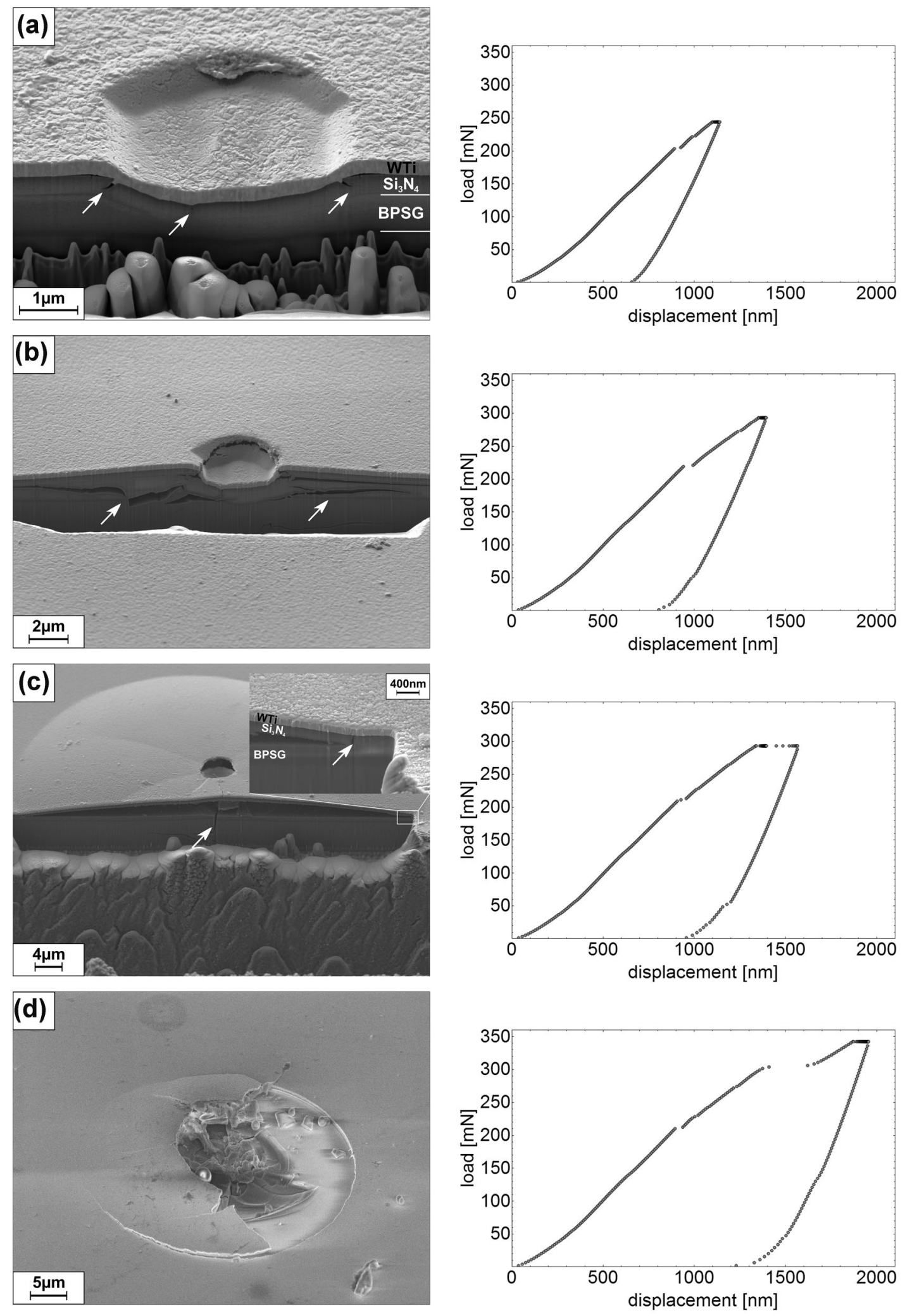

Fig. 4. FIB cross sections of indents made with loads of (a) $250 \mathrm{mN}$, (b) and (c) $300 \mathrm{mN}$, and (d) $350 \mathrm{mN}$. The load-displacement curves are shown next to the corresponding indent. The cross sections show the development of the interface crack and the fracture underneath the indenter with increasing load. The load-displacement curves reveal the pop-in events associated with the fracture and delamination events. Arrows indicate cracks of interest discussed in the text. 

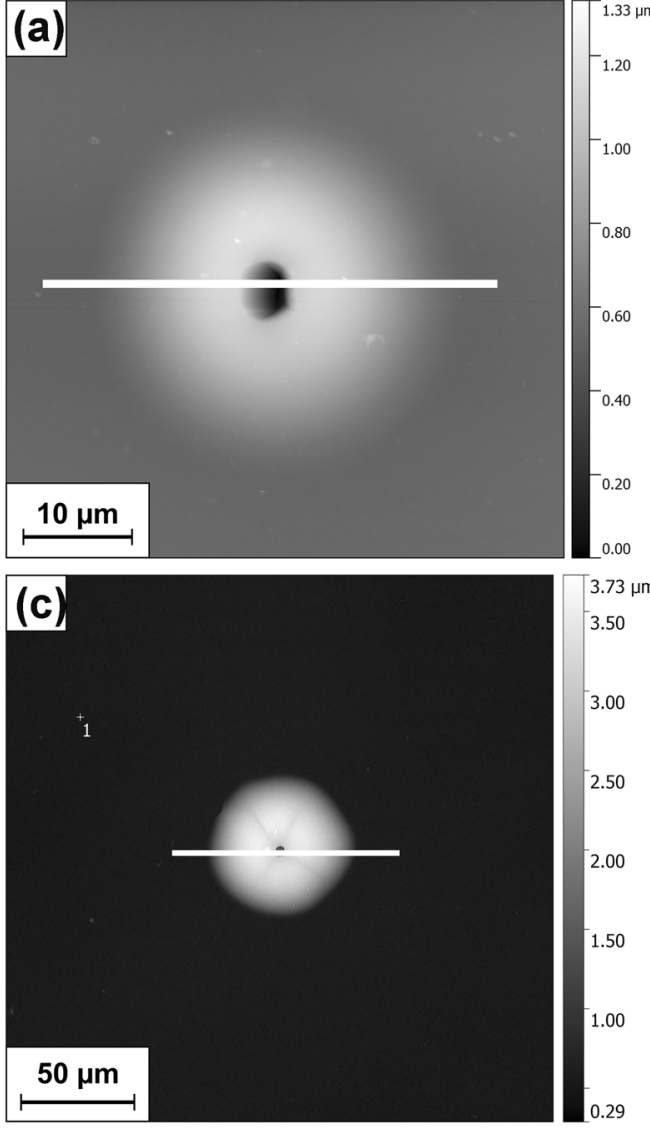

(b)

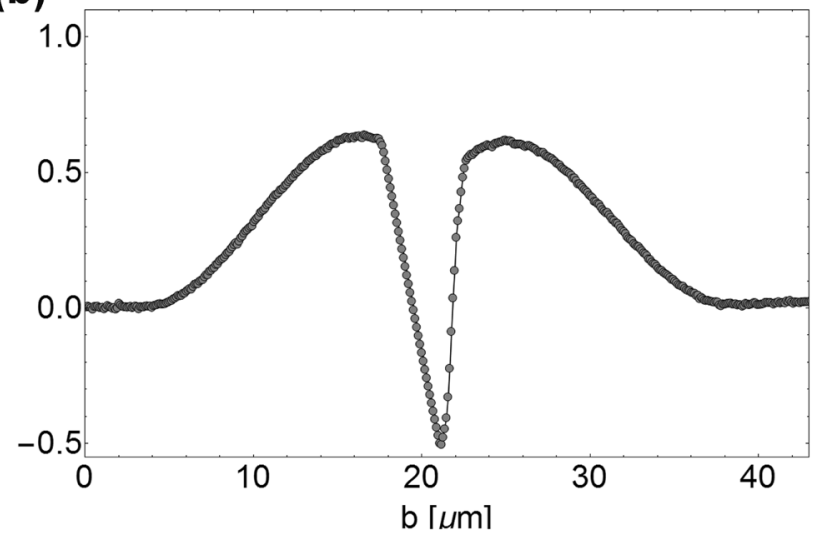

(d)

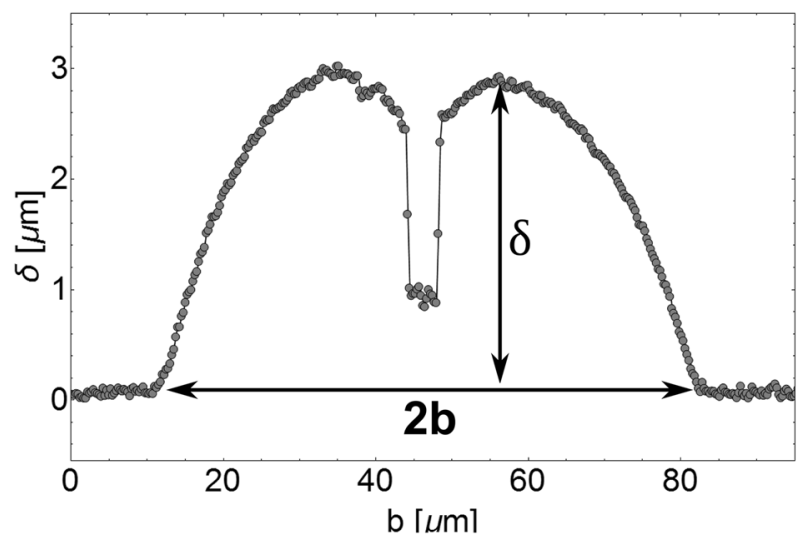

Fig. 5. AFM and CLSM images of indentation buckles, both produced by a load of $300 \mathrm{mN}$, with the white line indicating where the buckle is measured. (a) AFM image of a small buckle and (b) the according profile displaying an unpinned geometry. (c) Large buckle imaged with CLSM with the corresponding profile (d).

Table I. Summary of Average Half-Buckle Widths $(b)$, Buckling Stresses $\left(\sigma_{\mathrm{b}}\right)$, and Mixed-mode Adhesion Energies $(\Gamma(\Psi))$ from the Buckles Produced by Nanoindentation Shown in Figs. 3 and 4. Standard Deviations are Based on the Number of Measurements of Each Buckle Type (about 15-20 Measurements on 4-10 Buckles)

\begin{tabular}{lccc}
\hline Buckle type & Ave. $\mathbf{b}(\boldsymbol{\mu m})$ & Ave. $\boldsymbol{\sigma}_{\mathbf{b}}(\mathbf{M P a})$ & Ave. $\Gamma(\Psi)\left(\mathbf{J} / \mathbf{m}^{\mathbf{2}}\right)$ \\
Small (Fig. 4b) & $15.8 \pm 1.7$ & $525.7 \pm 115$ & $1.13 \pm 0.31$ \\
Large (Fig. 4c) & $31.7 \pm 2.8$ & $128.9 \pm 23$ & $1.35 \pm 0.28$ \\
Half (Fig. 3) & $30.9 \pm 4.2$ & $138.1 \pm 32$ & $1.36 \pm 0.16$ \\
Spalled (Fig. 4d) & $33.4 \pm 3.1$ & $116.2 \pm 22$ & - \\
\hline
\end{tabular}

large and small blisters, a large difference in buckling stresses is found even though the mixedmode adhesion energies of the buckles are only slightly different. As observed in Fig. 4b, the small buckle is a combination of multiple interface separations and film cracking, and as a result, the buckle dimensions cannot contribute to the failure of the specific $\mathrm{Si}_{3} \mathrm{~N}_{4}$-BPSG interface. Neither the Hutchinson and Suo model, nor the Marshall and Evans model, account for additional fracture events. The additional fracture events most likely inhibited the growth of the buckle half-width (interface crack) into a large buckle and led to the higher buckling stress. Therefore, the calculated values for the small buckles in Table I do not represent the true practical work of adhesion of the film system. The large buckles are mainly the result of the interface separation of the $\mathrm{Si}_{3} \mathrm{~N}_{4}$ and the BPSG (Fig. 4c), and the values of $\Gamma(\Psi)$ in Table I are the true practical adhesion energies of this interface. Additionally, irregularly shaped buckles, where a portion of the buckle was spalled off the surface or did not develop as a result of the radial cracking (Fig. 3), have been investigated. The half-buckles 
were measured in a way that included only the unspalled or fully developed part of the buckle (Fig. 4d). The results show that the calculated values are in good agreement with the full buckles and demonstrated that they can be used to measure adhesion. Finally, the widths of the completely spalled buckles were measured to calculate the buckling stress compared with the large and halfbuckles, and the buckling stress was only slightly lower compared with the unspalled buckles. What Table I demonstrates is that with proper characterization of the failing interface, not only the "ideal" buckles can be used to evaluate the adhesion energy with nanoindentation, but also irregular buckles without too much additional substrate fracture are valuable (compare large and half-buckles). The $\Gamma(\Psi)$ are reasonable for ceramic-ceramic interfaces and agree well with $\mathrm{Ma}$ et al. ${ }^{32}$ where the adhesion energy of a $\mathrm{Si}_{x} \mathrm{~N}_{y} / \mathrm{SiO}_{2}$ interface was reported to be $1.2-1.8 \mathrm{~J} / \mathrm{m}^{2}$. The values are also in the same range of some metal-glass systems, for instance, $\mathrm{Pt} / \mathrm{Ti}$ on $\mathrm{SiO}_{2}$, which was determined to be $1.8 \mathrm{~J} / \mathrm{m}^{2} .{ }^{12}$

It should be noted that nanoindentation-induced delamination has a few limitations. For example, the technique should only be applied to film systems on rigid substrates. Nanoindentation-induced delamination will not work for films on compliant/ polymer substrates or with compliant layers. Some plastic deformation is necessary to induce the delamination and compliant substrates, at the loads typically used, only elastically deform. Also, typically large indentation loads are needed; therefore, one would need a nanoindenter capable of at least $100 \mathrm{mN}$ and higher loads. Post-analysis of the delaminating interface is necessary, but FIB does not have to be used. A simple peel test or careful removal of a buckle can be used to determine the failing interface. ${ }^{33}$ Nevertheless, this does not help for the separation of fracture events from the interface fracture when multiple layers or pop-ins are present in the load-displacement curves. Finally, it is best to make several indents at various loads to understand fully the film deformation, film fracture, and interface fracture processes.

\section{SUMMARY}

The adhesion energy of a $\mathrm{Si}_{3} \mathrm{~N}_{4}$-BPSG interface has been determined through the use of nanoindentation-induced delaminations and a stressed overlayer. As a result of the support of the compressive WTi stressed overlayer, nanoindentation can be employed to delaminate and subsequently buckle this interface. The elastic deformation of the metal film induces the necessary stress into the system to cause interface separation and forces the rigid $\mathrm{Si}_{3} \mathrm{~N}_{4}$ film to buckle as a circular buckle. The development of interface separation and buckling falls into a narrow load range between $300 \mathrm{mN}$ and $350 \mathrm{mN}$ for this tip geometry. Loads of $300 \mathrm{mN}$ and greater led to the development of $\mathrm{Si}_{3} \mathrm{~N}_{4}$-BPSG interface separation, indicated by a large pop-in. The adhesion energy of the interface calculated from the large and half indentation buckles are in good agreement and show that the adhesive strength of this interface is low and comparable with other ceramic-ceramic interfaces. A brittle film can buckle under the right experimental conditions when supported by an elastic compressively stressed overlayer, making this mechanical test method viable for adhesion testing for film systems in microelectronics. Because every multilayered thin film system may behave differently, complete characterization of the failing interface and loaddisplacement curves should be carried out to calculate the adhesion energies properly. Nevertheless, nanoindentation-induced delamination is a versatile technique that can be easily implemented for a variety of interfaces, especially when augmented by FIB, CLSM, and AFM characterization techniques.

\section{ACKNOWLEDGEMENTS}

This work was jointly funded by the Austrian Research Promotion Agency (FFG: Project No. 846579) and the Carinthian Economic Promotion Fund (KWF, Contract KWF-1521/26876/38867). Additional financial support from the Austrian Federal Government (837900) within the framework of the COMET Funding Program is appreciated.

\section{OPEN ACCESS}

This article is distributed under the terms of the Creative Commons Attribution 4.0 International License (http://creativecommons.org/licenses/by/4.0/), which permits unrestricted use, distribution, and reproduction in any medium, provided you give appropriate credit to the original author(s) and the source, provide a link to the Creative Commons license, and indicate if changes were made.

\section{ELECTRONIC SUPPLEMENTARY MATERIAL}

The online version of this article (doi:10.1007/ s11837-017-2496-2) contains supplementary material, which is available to authorized users.

\section{REFERENCES}

1. K.L. Mittal, Electrocompon. Sci. Technol. 3, 21 (1976).

2. C. Weaver, J. Vac. Sci. Technol. A Vac. Surf. Film 12, 18 (1975).

3. B.N. Chapman, J. Vac. Sci. Technol. A Vac. Surf. Film 11, 106 (1974).

4. A. Bagchi and A.G. Evans, Interface Sci. 3, 163 (1996).

5. D.B. Marshall and A.G. Evans, J. Appl. Phys. 56, 2632 (1984).

6. C. Rossington, A.G. Evans, D.B. Marshall, and B.T. KhuriYakub, J. Appl. Phys. 56, 2639 (1984).

7. M.D. Thouless, E. Olsson, and A. Gupta, Acta Metall. Mater. 40, 1287 (1992).

8. M.D. Thouless, Eng. Fract. Mech. 61, 75 (1998). 
9. M.D. Kriese, W.W. Gerberich, and N.R. Moody, J. Mater. Res. 14, 3007 (1999).

10. J.W. Hutchinson and Z. Suo, Adv. Appl. Mech. 29, 63 (1992).

11. M. Ortiz and G. Gioia, J. Mech. Phys. Solids 42, 531 (1994).

12. M.J. Cordill, D.F. Bahr, N.R. Moody, and W.W. Gerberich, IEEE Trans. Device Mater. Reliab. 4, 163 (2004).

13. W.W. Gerberich and M.J. Cordill, Rep. Prog. Phys. 69, 2157 (2006).

14. A.A. Volinsky, N.R. Moody, and W.W. Gerberich, Acta Mater. 50, 441 (2002).

15. R.P. Birringer, P.J. Chidester, and R.H. Dauskardt, Eng. Fract. Mech. 78, 2390 (2011).

16. J. Faou, G. Parry, S. Grachev, and E. Barthel, J. Mech. Phys. Solids 75, 93 (2015).

17. A. Roshanghias, G. Khatibi, R. Pelzer, and J. Steinbrenner, Surf. Coat. Technol. 259, 386 (2014).

18. M. Omiya, K. Koiwa, N. Shishido, S. Kamiya, C. Chen, H. Sato, M. Nishida, T. Suzuki, T. Nakamura, T. Suzuki, and T. Nokuo, Microelectron. Reliab. 53, 612 (2013).

19. R. Konetschnik, R. Daniel, R. Brunner, and D. Kiener, AIP Adv. 7, 035307 (2017).

20. K. Matoy, T. Detzel, M. Müller, C. Motz, and G. Dehm, Surf. Coat. Technol. 204, 878 (2009).
21. M.J. Cordill, F.D. Fischer, F.G. Rammerstorfer, and G. Dehm, Acta Mater. 58, 5520 (2010).

22. V.M. Marx, C. Kirchlechner, I. Zizak, M.J. Cordill, and G. Dehm, Philos. Mag. 95, 1982 (2015).

23. M.J. Cordill, O. Glushko, and B. Putz, Front. Mater. 3, 1 (2016).

24. D.F. Bahr, J.W. Hoehn, N.R. Moody, and W.W. Gerberich, Acta Mater. 45, 5163 (1997).

25. D. Nečas and P. Klapetek, Open Phys. 10, 181 (2012).

26. J.J. Vlassak and W.D. Nix, J. Mater. Res. 7, 3242 (1992).

27. M.P. Echlin, M. Straw, S. Randolph, J. Filevich, and T.M. Pollock, Mater. Charact. 100, 1 (2015).

28. M.P. Echlin, M.S. Titus, M. Straw, P. Gumbsch, and T.M. Pollock, Acta Mater. 124, 37 (2017).

29. M.J. Pfeifenberger, M. Mangang, S. Wurster, J. Reiser, A. Hohenwarter, W. Pfleging, D. Kiener, and R. Pippan, $M a-$ ter. Des. 121, 109 (2017).

30. A. Kleinbichler, J. Zechner, and M.J. Cordill, Microelectron. Eng. 167, 63 (2017).

31. A. Kleinbichler, M. Bartosik, B. Völker, and M.J. Cordill, Adv. Eng. Mater. 19, 1600665 (2017)

32. Q. Ma, J. Mater. Res. 12, 840 (1997).

33. M.J. Cordill, N.R. Moody, and D.F. Bahr, J. Mater. Res. 19, 1818 (2004). 